\title{
Analysis of the thermal decomposition of azo-peroxyesters by Arrhenius-type and three-parameter equations
}

\author{
B. Hefczyc $\cdot$ T. Siudyga $\cdot$ J. Zawadiak $\cdot$ \\ A. Mianowski
}

Received: 16 August 2010/Accepted: 29 March 2011/Published online: 16 April 2011

(C) The Author(s) 2011. This article is published with open access at Springerlink.com

\begin{abstract}
Thermogravimetric analysis of azo-peroxyesters revealed two decomposition stages on TG curves. Molecular nitrogen is released in the first stage and carbon dioxide in the second. Fitting the thermogravimetric data by means of the three-parameter model and a classic one based on an Arrhenius-type kinetic equation showed that the former approach satisfactorily describes the process within the wide range of the extent of decomposition. It was found that two coefficients of the three-parameter equation are related to the temperature of maximum reaction rate. One of the coefficients of the three-parameter equation is also related to the activation energy. The compounds investigated can be grouped with respect to their kinetic characteristics, structure and stage of decomposition.
\end{abstract}

Keywords Azo-peroxyesters - Thermal decomposition · Kinetic analysis - Approximation of TG with three-parameter equation $\cdot$ Relative rate of reaction

\section{Introduction}

There are growing demands in different branches of industry for polymeric materials with customized physical

B. Hefczyc · J. Zawadiak

Department of Chemical Organic Technology

and Petrochemistry, Silesian University of Technology,

B. Krzywoustego 4, 44-100 Gliwice, Poland

T. Siudyga $(\bowtie) \cdot$ A. Mianowski

Department of Chemistry, Inorganic Technology and Fuels,

Silesian University of Technology, B. Krzywoustego 6,

44-100 Gliwice, Poland

e-mail: tomasz.siudyga@polsl.pl and chemical properties. This has prompted investigations into new types of polymers and new polymerization techniques. It is difficult, however, to design homopolymeric materials with customized properties: it is much easier to design block or star-like copolymers, for example. To obtain such materials numerous polymerization techniques and different bi- and polyfunctional initiators are used. Such initiators contain two or more identical or different groups in their structure that can initiate polymerization according to radical or ionic mechanisms. In this way, block, linear and branched copolymers can be obtained [1].

Azo-peroxy compounds containing azo and peroxy groups (of different thermal and photochemical stability) in their structure are bifunctional initiators. These compounds can initiate polymerization at various copolymerization stages according to a free radical chain mechanism. The polymerization of various unsaturated monomers initiated by azo-peroxyesters has been tested [2-4].

The details of the synthesis of azo-peroxyesters by the reaction of sodium salts of organic hydroperoxides with acid chlorides, as well as investigations of their spectroscopic features and stability are given elsewhere [5]. On the other hand, peroxy and azo compounds have been analysed by isothermal and dynamic thermoanalytical methods [6-8]. These investigations enable the activation energies for decomposition, decomposition rate constants at different temperatures, and thermal ranges of decomposition to be determined. The kinetic data enables the conditions of polymerization under which these compounds are used as initiators to be established. Thermal analysis also supplies information on the safe storage and handling of the compounds [2]. We found that in the case of compounds containing both azo and peroxy groups it is more convenient to perform analyses under dynamic conditions with a constant rate of temperature increase [2]. 
<smiles>[R]OOC(=O)CCCCCC(C)(C#N)N=NC(C)(C#N)CCCC(=O)OO[R]</smiles>

Scheme 1 The compounds investigated: $1(n=2, \mathrm{R}=t$-Bu), $2(n=3, \mathrm{R}=t-\mathrm{Bu}), 3(n=4, \mathrm{R}=t-\mathrm{Bu}), 4(n=2, \mathrm{R}=t-\mathrm{Am})$, $5(n=3, \mathrm{R}=t-\mathrm{Am}), \mathbf{6}(n=4, \mathrm{R}=t-\mathrm{Am})$

Here we report the results of thermoanalytical investigations of compounds containing tert-butyl $(t-\mathrm{Bu})$ and tertamyl ( $t$-Am) substituents and alkyl chains of different length between the azo and peroxy groups (Scheme 1).

The results of DSC investigations of these compounds showed that in the first stage, at lower temperatures, azo groups decompose, while at higher temperatures, the peroxyester fragments break down [5]. $\mathrm{N}_{2}$ is released in the first stage and $\mathrm{CO}_{2}$ in the second (Scheme 2).

DSC analyses revealed that both stages are partially superimposed. Additionally the endothermic signal of melting overlaps with the signal of the first decomposition stage, which made the analysis difficult. That is why we used dynamic thermogravimetric analysis and complex kinetic analysis to describe the overall chemical changes during the decomposition of the compound investigated.

\section{Experimental}

The compounds investigated were synthesized as described elsewhere [5]. Thermogravimetric measurements were carried out using a Mettler Toledo TGA/SDTA-851 instrument under the following conditions: platinum crucible, sample mass $1-1.5 \mathrm{mg}$, heating rate $1-6 \mathrm{~K} \mathrm{~min}^{-1}$, $\mathrm{N}_{2}$ atmosphere (gas flow rate, $100 \mathrm{~cm}^{3} \mathrm{~min}^{-1}$ ).

\section{Results}

Examples of TG and DTG curves for the compounds investigated (1-3) are presented in Fig. 1. Two quite wellresolved decomposition stages are seen. $\mathrm{N}_{2}$ is released in the first stage, $\mathrm{CO}_{2}$ in the second. Analysis of mass loss on the basis of TG curves indicates that in the second stage volatile products other than $\mathrm{CO}_{2}$ are formed (the mass loss is greater than that predicted from the stoichiometry of the reactions shown in Scheme 2). The further mass loss (at higher temperatures) seen in TG curves is difficult to ascribe by any simple chemical process. The characteristic temperatures extracted from DTG curves, $T_{\mathrm{i}}$ and $T_{\mathrm{m}}$, i.e. temperatures of the onset of decomposition and the maximum of the DTG peak, respectively, are presented in Table 1. Analysis of these characteristic temperatures indicates that decomposition of all samples occurs in a similar temperature range, from $357-364 \mathrm{~K}$ to $398-403 \mathrm{~K}$, in the first stage and from $398-403 \mathrm{~K}$ to $450-453 \mathrm{~K}$ in the

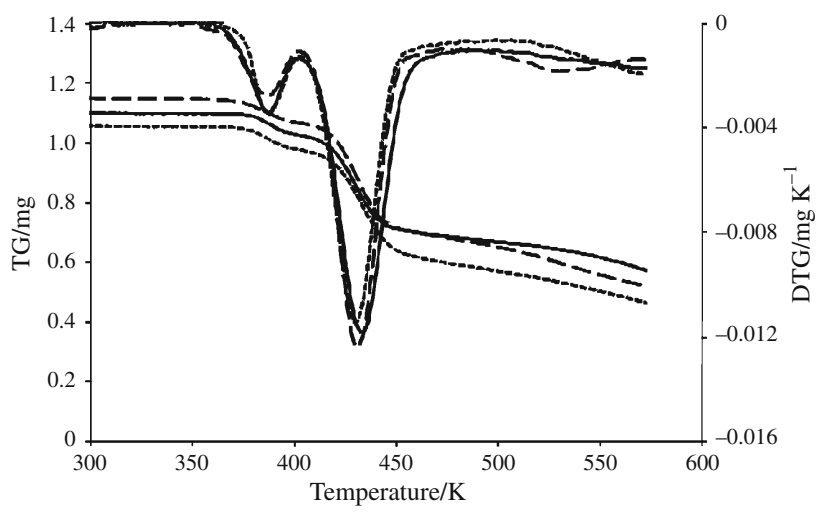

Fig. 1 TG and DTG curves for compounds 1-3: 1 (solid line), $\mathbf{2}$ (long dashed line), $\mathbf{3}$ (short dashed line) (for details see Scheme 1)
Scheme 2 Thermal decomposition pathways of azoperoxyesters

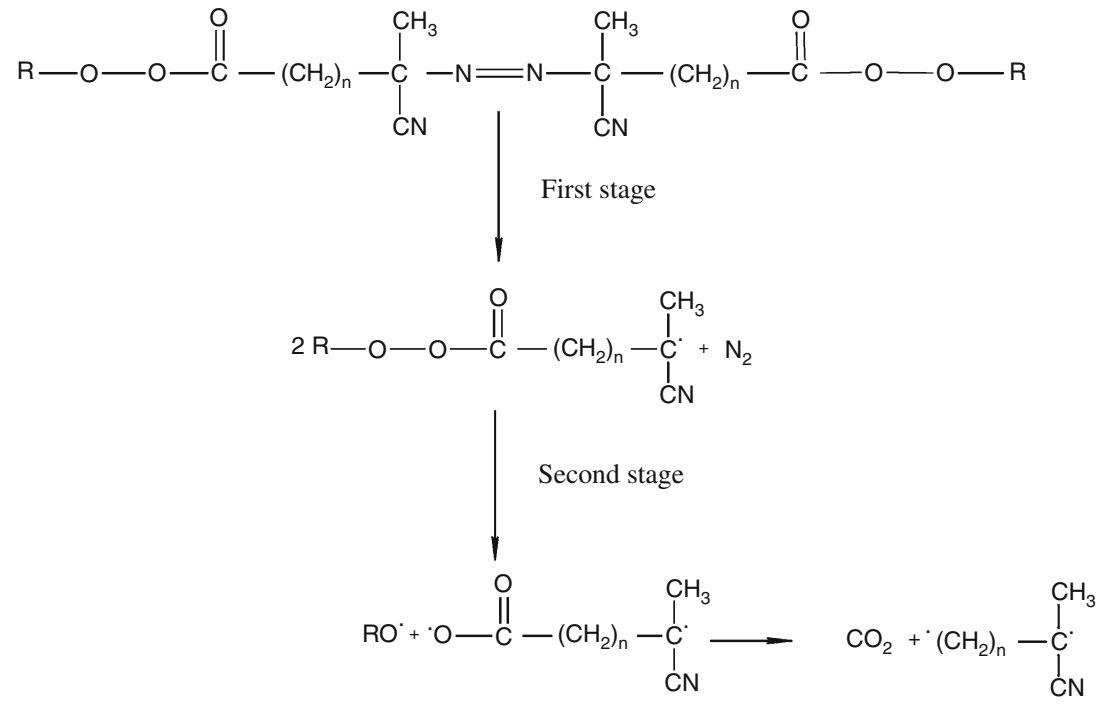


Table 1 Characteristic temperatures of the thermal decomposition of azo-peroxyesters

\begin{tabular}{llllll}
\hline Compound no. $^{\mathrm{a}}$ & \multicolumn{2}{l}{ First stage $^{\mathrm{b}}$} & & \multicolumn{2}{c}{ Second stage $^{\mathrm{b}}$} \\
\cline { 2 - 3 } & $T_{\mathrm{i}}$ & $T_{\mathrm{m}}$ & & $T_{\mathrm{i}}$ & $T_{\mathrm{m}}$ \\
\hline $\mathbf{1}$ & 363 & 387 & & 402 & 432 \\
$\mathbf{2}$ & 364 & 386 & & 401 & 429 \\
$\mathbf{3}$ & 369 & 384 & 402 & 428 \\
$\mathbf{4}$ & 357 & 383 & 398 & 426 \\
$\mathbf{5}$ & 361 & 386 & 403 & 424 \\
$\mathbf{6}$ & 359 & 387 & 399 & 425 \\
\hline
\end{tabular}

${ }^{a}$ For details see Scheme 1

b Temperatures in $\mathrm{K}$

second stage. Compounds 4-6 generally decompose at somewhat lower temperatures than 1-3. This may be due to differences in their chemical structure-different $\mathrm{R}$ (Scheme 1).

\section{Discussion}

The thermal decomposition of azo-peroxyesters proceeds in two stages reflected by the two peaks on the TG curves. Methods based on Arrhenius-type kinetic equations are usually used to fit thermogravimetric data and to determine kinetic parameters [9-13]. These methods are widely applied in the case of dynamic measurements carried out at different heating rates. In this paper, the thermogravimetric data obtained at one heating rate was analysed with Arrhenius-type and three-parameter equations.

Arrhenius-type equation

The differential kinetic equation for dynamic conditions takes the form $\frac{\mathrm{d} \alpha}{\mathrm{d} T}=\frac{A}{q} f(\alpha) e^{-E / R T}$

where $\alpha$ the extent of reaction, $T$ temperature, $A$ preexponential factor, $E$ activation energy, $R$ gas constant, $q$ heating rate $(\mathrm{d} T / \mathrm{d} \tau=$ const, $\tau$ time $)$ and $f(\alpha)$ differential function reflecting the kinetic model of the process.

After integration of Eq. 1 one obtains

$g(\alpha)=\int_{0}^{\alpha} \frac{\mathrm{d} \alpha}{f(\alpha)}=\frac{\mathrm{A}}{q} \int_{0}^{T} \mathrm{e}^{-E / R T} \mathrm{~d} T$

where $g(\alpha)$ the integral function representing the kinetic model of the process. We applied the Coats-Redfern approximation $[14,15]$ of the temperature integral in Eq. 2, which gives the following equations [16]

$g(\alpha)=\frac{A R T^{2}}{q E} \mathrm{e}^{-E / R T}$

$\ln \frac{\mathrm{g}(\alpha)}{T^{2}}=\ln \frac{A R}{q E}-\frac{E}{R T}$

To obtain the kinetic parameters from Eq. 1, $f(\alpha)$ functions were selected using the criteria proposed in [17].

Average activation energies $(\bar{E})$ were calculated for selected models from the relationship

$\bar{E}=\frac{1}{N} \sum \frac{E}{b}$

where $N$ the number of models and $b$ the coefficient for the model ( 1 for $\mathrm{F}$ and $\mathrm{R}, 1 / 2$ for $\mathrm{A} 2,1 / 3$ for $\mathrm{A} 3$ and 2 for $\mathrm{D}$ ).

The results are presented in Table 2. There are significant differences in $E$ values for the first stage of decomposition. Moreover, both stages of decomposition are well described by the F1, A2 and A3 models, and that in the majority of cases the F1 model gives the best fit.

The results indicate the existence of the isokinetic effect-a linear relationship between the logarithm of the

Table 2 Average activation energies and pre-exponential factors obtained by fitting thermogravimetric data for azo-peroxyesters with an Arrhenius-type equation

\begin{tabular}{|c|c|c|c|c|c|c|}
\hline \multirow[t]{2}{*}{ Compound no. $^{\mathrm{a}}$} & \multicolumn{3}{|l|}{ First stage $^{\mathrm{b}}$} & \multicolumn{3}{|c|}{ Second stage ${ }^{b}$} \\
\hline & $\overline{\bar{E} / \mathrm{kJ} \mathrm{mol}}{ }^{-1}$ & $\ln \bar{A}$ & $r^{2}>0.98$ & $\bar{E} / \mathrm{kJ} \mathrm{mol}^{-1}$ & $\ln \bar{A}$ & $r^{2}>0.98$ \\
\hline 1 & 188 & 17.1 & $\mathrm{~F} 1, \mathrm{~A} 2, \mathrm{~A} 3$ & 182 & 13.0 & $\mathrm{~F} 1, \mathrm{~A} 2, \mathrm{~A} 3$ \\
\hline 2 & 169 & 14.1 & $\mathrm{~F} 1, \mathrm{~A} 2, \mathrm{~A} 3$ & 195 & 14.8 & $\mathrm{~F} 1, \mathrm{~A} 2, \mathrm{~A} 3$ \\
\hline 3 & 223 & 22.3 & $\mathrm{~F} 1, \mathrm{~A} 2, \mathrm{~A} 3$ & 188 & 14.0 & $\mathrm{~F} 1, \mathrm{~A} 2, \mathrm{~A} 3$ \\
\hline 4 & 153 & 11.7 & $\mathrm{~F} 1, \mathrm{~A} 2, \mathrm{~A} 3$ & 183 & 13.4 & $\mathrm{~F} 1, \mathrm{~A} 2, \mathrm{~A} 3$ \\
\hline 5 & 150 & 11.2 & $\mathrm{~F} 1, \mathrm{~A} 2, \mathrm{~A} 3$ & 180 & 13.0 & $\mathrm{~F} 1, \mathrm{~A} 2, \mathrm{~A} 3$ \\
\hline 6 & 143 & 10.1 & $\mathrm{~F} 1, \mathrm{~A} 2, \mathrm{~A} 3$ & 175 & 12.2 & $\mathrm{~F} 1, \mathrm{~A} 2, \mathrm{~A} 3$ \\
\hline
\end{tabular}

${ }^{\text {a }}$ For details see Scheme 1

${ }^{\text {b }} \bar{E}$ values were calculated using Eq. $5 ; \ln \bar{A}$ values were calculated by replacing $E$ with $\ln A$ in Eq. $5 ; r^{2}$ represents the determination coefficient 


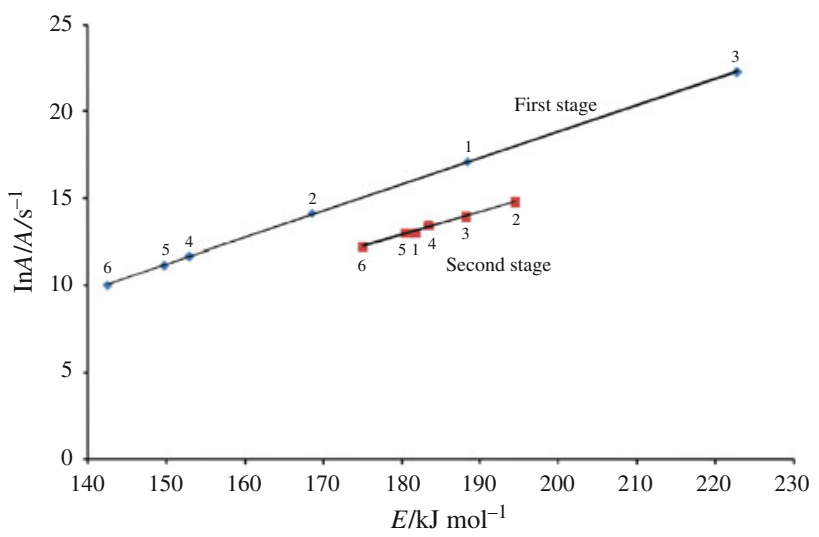

Fig. 2 Isokinetic effect in the thermal decomposition of azoperoxyesters (numbers indicate the compounds investigated-for details see Scheme 1)

pre-exponential factor and the activation energy (Fig. 2) [18]. The straight lines resulting from the approximation have the following analytical forms

$\ln \bar{A}=1.52 \times 10^{-4} \bar{E}-11.6 \quad r^{2}=1.000$ (first stage)

$\ln \bar{A}=1.30 \times 10^{-4} \bar{E}-10.6 \quad r^{2}=0.994$ (second stage)

In Fig. 2 the points related to compounds 1-3 are placed on the left-hand side, whereas those corresponding to compounds 4-6 are on the right-hand side. In the first stage of the decomposition, the points representing compounds 1-3 and 4-6 are more widely separated than in the second stage. Values of $E\left(175-195 \mathrm{~kJ} \mathrm{~mol}^{-1}\right)$ for the second stage $\left(\mathrm{CO}_{2}\right.$ removal $)$ are similar to those found for other organic compounds $[19,20]$, but are lower than the ones determined for the decomposition of calcium carbonate [9].

\section{Three-parameter equation}

Following [17] we applied the three-parameter model to the TG curve fitting, which links the extent of reaction $(\alpha)$ with temperature $(T)$ without the integral $g(\alpha)$. The model is represented by the equation [21]

$\ln \alpha=a_{0}-\frac{a_{1}}{T}-a_{2} \ln T$

where $a_{0}, a_{1}$ and $a_{2}$ are characteristic coefficients related to the kinetics and thermodynamics of the thermal decomposition.

The three-parameter equation arising from the van't Hoff's isobar enables the dissociation enthalpy to be determined, since it is proportional to $\ln \alpha_{\text {eq }} /\left(1 / T_{\text {eq }}\right)-$ $(1 / T)$ (where $\alpha_{\mathrm{eq}}$ and $T_{\mathrm{eq}}$ denote the extent of reaction and temperature, respectively, under equilibrium conditions) [22]. It was found that $a_{2}$ changes linearly with changes of

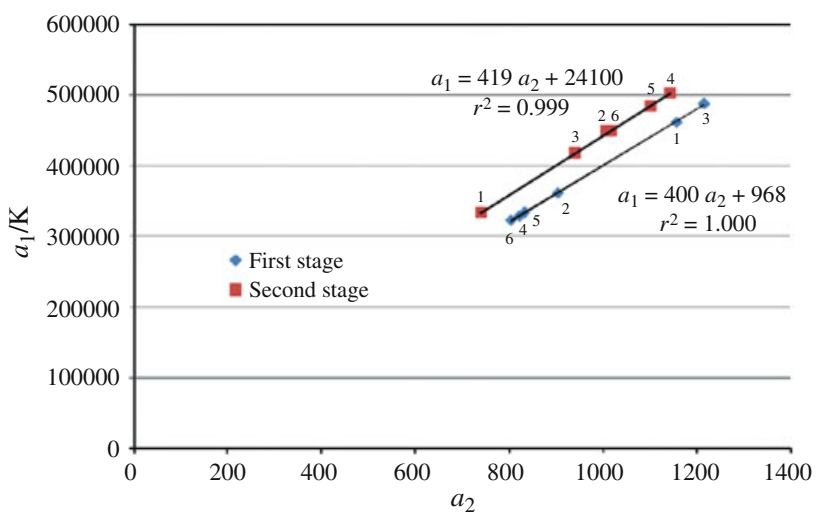

Fig. 3 Relationships between coefficients in the three-parameter equation (numbers indicate the compounds investigated-for details see Scheme 1)

both $a_{0}$ and $a_{1}$ [23-26]. Figure 3 shows one of these dependences for the compounds investigated.

The differentiation and transformation of Eq. 8 yields the relationship for the relative rate $(r)$ expressed by the formula [26]

$r=\frac{\mathrm{d} \alpha / \mathrm{d} T}{\alpha} T^{2}=-\frac{\mathrm{d} \ln \alpha}{\mathrm{d}(1 / T)}=a_{1}-a_{2} T$

Further transformation of Eq. 9 produces relationship 10 determining the zero-order temperature profile [24]

$r=\frac{T^{2}}{T-T_{\mathrm{i}}}=T+T_{\mathrm{i}}+\frac{T_{\mathrm{i}}^{2}}{T-T_{\mathrm{i}}}$

In the kinetic analysis we also applied the relationships 11 and 12 that we derived earlier [27]

$r_{\mathrm{m}}=T_{\mathrm{m}}\left(1+\sqrt{1+a_{2}}\right)$

And

$r_{\mathrm{m}}=a_{1}-a_{2} T_{\mathrm{m}}$

where $r_{\mathrm{m}}$ represents the maximum reaction rate.

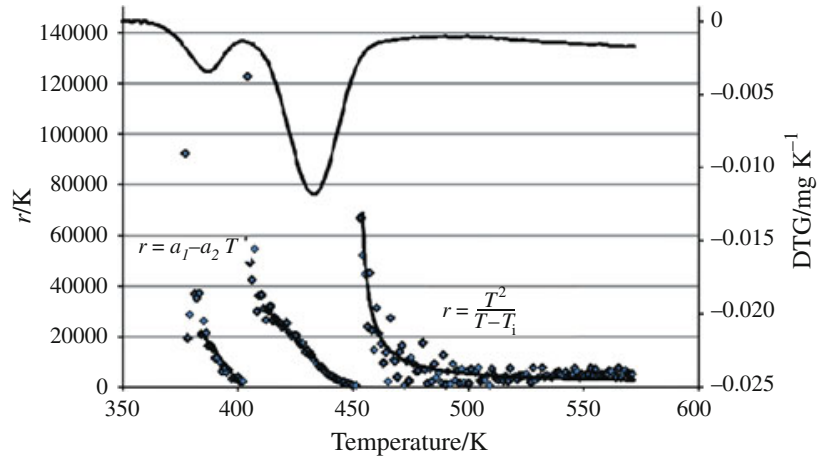

Fig. 4 Relationship of $r$ versus $T$ for compound 1 (for details see Scheme 1) 
Table 3 Coefficients obtained from the fitting of thermogravimetric data with the three-parameter equation

\begin{tabular}{|c|c|c|c|c|c|c|c|c|c|c|}
\hline \multirow[t]{2}{*}{ Compound no. ${ }^{\mathrm{a}}$} & \multicolumn{5}{|c|}{ First stage $^{\mathrm{b}}$} & \multicolumn{5}{|c|}{ Second stage ${ }^{b}$} \\
\hline & $\overline{a_{1} \times 10^{3}}$ & $a_{2}$ & $r^{2}$ & $T_{\mathrm{m}}$ & $\Delta T_{\mathrm{m}}$ & $\overline{a_{1} \times 10^{3}}$ & $a_{2}$ & $r^{2}$ & $T_{\mathrm{m}}$ & $\overline{\Delta T_{\mathrm{m}}}$ \\
\hline 1 & 462 & 1155 & 0.940 & 387 & -0.5 & 333 & 739 & 0.982 & 432 & -2.3 \\
\hline 2 & 361 & 904 & 0.916 & 386 & -0.4 & 449 & 1010 & 0.971 & 429 & -2.2 \\
\hline 3 & 488 & 1215 & 0.929 & 384 & -6.0 & 418 & 939 & 0.969 & 428 & -2.5 \\
\hline 4 & 329 & 822 & 0.907 & 383 & -3.5 & 502 & 1140 & 0.991 & 426 & -0.8 \\
\hline 5 & 334 & 833 & 0.915 & 386 & -1.1 & 484 & 1100 & 0.985 & 424 & -2.9 \\
\hline 6 & 323 & 804 & 0.901 & 387 & -0.8 & 449 & 1020 & 0.985 & 425 & -1.8 \\
\hline
\end{tabular}

${ }^{a}$ Values $a_{1}, T_{\mathrm{m}}$ (calculated) and $\Delta T_{\mathrm{m}}$ are in $\mathrm{K}$; values of $a_{1}$ and $a_{2}$ were obtained by fitting Eq. 8 to thermogravimetric data; values of $T_{\mathrm{m}}$ (calculated) were derived by using Eq. $13 ; \Delta T_{\mathrm{m}}=T_{\mathrm{m}}$ (calculated) $-T_{\mathrm{m}}$ (measured)

By combining Eqs. 11 and 12 one obtains a relationship that links coefficients $a_{1}$ and $a_{2}$ with the temperature of the maximum reaction rate

$a_{1}=T_{\mathrm{m}}\left(1+a_{2}+\sqrt{1+a_{2}}\right)$

Plots of reaction rate $(r)$ versus temperature $(T)$ are presented in Fig. 4. Their linear sections correspond to a quite wide range of $\alpha$ values from 0.2 to 0.9 for the first stage and from 0.05 to 0.9 for the second one. This follows previous findings, which show that it is more convenient to apply the relative rate of thermal decomposition than the hitherto used DTG data (Fig. 1). Values of $a_{1}, a_{2}, T_{\mathrm{m}}$ (calculated from Eq. 12) and $\Delta T_{\mathrm{m}}$ for both decomposition stages are presented in Table 3. If we take relationship 9 into account, we see that an increase in $a_{2}$ also leads to an increase in reaction rate $(r)$ in terms of $\mathrm{d} \alpha / \mathrm{d} T$, but not always in terms of $\mathrm{d} \alpha / \mathrm{d} \tau$, which is considered to be the primary formula for the determination of $r$ [28]. According to our investigations, $a_{0}$ and $a_{1}$ increase when $a_{2}$ does so. Calculated values of $T_{\mathrm{m}}$ are generally higher than its measured values, although both sets of values correspond

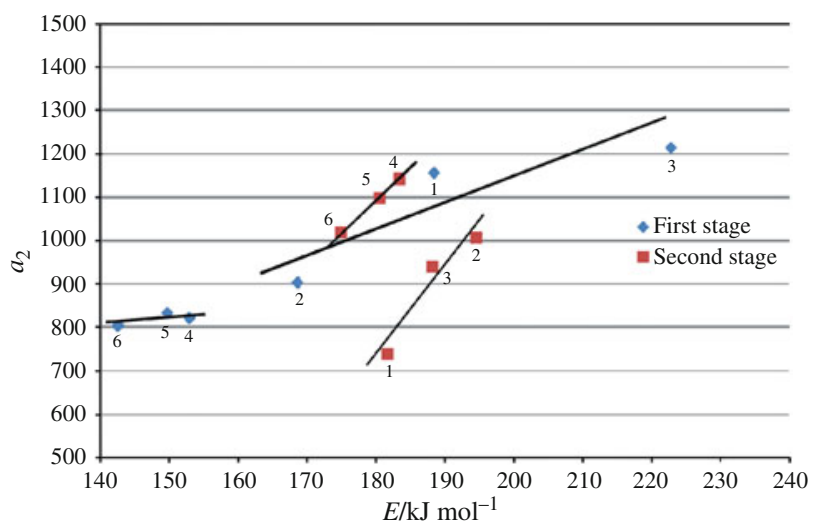

Fig. 5 Dependence of $a_{2}$ coefficient versus activation energy $(E)$ for azo-peroxyesters (numbers indicate the compounds investigated-for details see Scheme 1) quite well to each other. This implies that our approach is reliable.

Values of $a_{2}$ are relatively high: $804-1215$ for the first stage of thermal decomposition and 739-1140 for the second. They are typical of chemical processes rather than physical ones [17]. The rate of mass loss after these two stages can be obtained from relationship 10, which appears to be formally a zero-order activationless process [24].

Relations between $a_{2}$ and $E$ can be grouped on the basis of differences in the structures of the compounds (1-3 and 4-6) and the stages of decomposition (Fig. 5). Linear trends are observed for a given group of compounds and stage of the process. This may indicate that chemical structure is the main factor affecting the kinetic characteristics of thermal decomposition.

\section{Conclusions}

The thermal decomposition of azo-peroxyesters proceeds in two stages $-\mathrm{N}_{2}$ is released in the first and $\mathrm{CO}_{2}$ in the second. The mass loss seen on the TG curves indicates that after the second stage other volatile products are evolved (the mass loss is greater than that predicted from the stoichiometry of the reactions shown in Scheme 2).

The fitting of non-isothermal thermogravimetric data obtained at one heating rate using an Arrhenius-type kinetic equation provided an opportunity to determine the basic kinetic characteristics of the decomposition of azoperoxyesters. The isokinetic effect due to the chemical similarity of the samples was found to have occurred. The kinetic characteristics obtained by this approach do not discriminate the compounds investigated.

The three-parameter model fits the thermogravimetric data linearly within a wide range of the extent of decomposition. This follows previous findings, which showed that the relative rate of thermal decomposition is more convenient than the hitherto used DTG data. The results indicate 
that $a_{0}$ and $a_{1}$ increase as $a_{2}$ does so. Furthermore, the temperature of the maximum rate of decomposition is linked to $a_{1}$ and $a_{2}$. The predicted temperatures at which the rate of decomposition is a maximum correlate well with values of this quantity determined directly from DTG curves.

The results of this research confirm that the threeparameter model is more useful and convenient than the classical methods based on Arrhenius-type equations in the kinetic analysis of thermal decomposition processes.

Open Access This article is distributed under the terms of the Creative Commons Attribution Noncommercial License which permits any noncommercial use, distribution, and reproduction in any medium, provided the original author(s) and source are credited.

\section{References}

1. Bernaerts KV, Du Prez FE. Dual/heterofunctional initiators for the combination of mechanistically distinct polymerization techniques. Prog Polym Sci. 2006;31:671-722.

2. Pabin-Szafko B, Wisniewska E, Hefczyc B, Zawadiak J. New azo-peroxidic initiators in the radical polymerization of styrene and methyl methacrylate. Eur Polym J. 2009;45:1476-84.

3. Czech Z, Butwin A, Hefczyc B, Zawadiak J. Radical initiators and their influence on the viscosity and molecular weight of acrylic polymers applied in pressure-sensitive adhesives. Polimery. 2009;54:283-7.

4. Czech Z, Butwin A, Herko E, Hefczyc B, Zawadiak J. Novel azoperesters radical initiators used for the synthesis of acrylic pressure-sensitive adhesives. eXPRESS Polym Lett. 2008;2:277-83.

5. Zawadiak J, Hefczyc B, Janeczek H, Kowalczuk M. Synthesis and thermal properties of azo-peroxyesters. Monatsch Chem. 2009;140:303-8.

6. Severini F, Gallo R. DSC study of thermal decomposition of peroxide and azo derivative mixtures in the presence of LDPE. J Therm Anal Calorim. 1987;32:1189-200.

7. Cheikhalard T, Tighzert L, Pascault P. Thermal decomposition of some azo initiators. Influence of chemical structure. Angew Makromol Chem. 1998;256:49-59.

8. Severini F, Gallo R. Differential scanning calorimetry study of the thermal decomposition of peroxides in the absence of a solvent. J Therm Anal Calorim. 1985;30:841-7.

9. Brown ME, Maciejewski M, Vyazovkin S, Nomen R, Sempere J, Burnham A, Opfermann J, Strey R, Anderson HL, Kemmler A, Keuleers R, Janssens J, Desseyn HO, Li Ch-R, Tang TB, Roduit B, Malek J, Mitsuhashi T. Computational aspects of kinetic analysis.: Part A. The ICTAC kinetics project-data, methods and results. Thermochim Acta. 2000;355:125-43.

10. Maciejewski M. Computational aspects of kinetic analysis.: Part B. The ICTAC Kinetics Project-the decomposition kinetics of calcium carbonate revisited, or some tips on survival in the kinetic minefield. Thermochim Acta. 2000;355:145-54.

11. Vyazovkin S. Computational aspects of kinetic analysis.: Part C. The ICTAC Kinetics Project- the light at the end of the tunnel? Thermochim Acta. 2000;355:155-63.

12. Burnham AK. Computational aspects of kinetic analysis.: Part D. The ICTAC Kinetics Project-multi-thermal-history modelfitting methods and their relation to isoconversional methods. Thermochim Acta. 2000;355:165-70.

13. Roduit B. Computational aspects of kinetic analysis.: Part E. The ICTAC Kinetics Project-numerical techniques and kinetics of solid state processes. Thermochim Acta. 2000;355:171-80.

14. Coats AW, Redfern JP. Kinetic parameters from thermogravimetric data. Nature. 1964;201:68-9.

15. Coats AW, Redfern JP. Kinetic parameters from thermogravimetric data. II. J Polym Sci Part B: Polym Lett. 1965;3:917-20.

16. Mianowski A, Radko T. Evaluation of the solutions of a standard kinetic equation for non-isothermal conditions. Thermochim Acta. 1992;204:281-93.

17. Mianowski A, Siudyga T. Influence of sample preparation on thermal decomposition of wasted polyolefins-oil mixtures. J Therm Anal Calorim. 2008;92:543-52.

18. Mianowski A, Bigda R. The Kissinger law and isokinetic effect: Part II. Experimental analysis. J Therm Anal Calorim. 2004;75: 355-72.

19. Criado JM, Gonzalez M, Malek J, Ortega A. The effect of the $\mathrm{CO}_{2}$ pressure on the thermal decomposition kinetics of calcium carbonate. Thermochim Acta. 1995;254:121-7.

20. Britt PF, Buchanan AC, Eskay TP, Mungall WS. Mechanistic investigations into the decarboxylation of aromatic carboxylic acids. American Chemical Society National Meeting, New Orleans, LA, August 22-26, 1999.

21. Mianowski A. Thermal dissociation in dynamic conditions by modeling thermogravimetric curves using the logarithm of conversion degree. J Therm Anal Calorim. 2000;59:747-62.

22. Šesták J. Heat, thermal analysis and society. Hradec Králové: Nucleus HK; 2004.

23. Mianowski A, Bigda R. Thermodynamic interpretation of threeparametric equation: Part I. New form of equation. J Therm Anal Calorim. 2003;74:423-32.

24. Mianowski A, Bigda R, Zymla V. Study on kinetics of combustion of brick-shaped carbonaceous materials. J Therm Anal Calorim. 2006;84:563-74.

25. Mianowski A, Blazewicz S, Robak Z. Analysis of the carbonization and formation of coal tar pitch mesophase under dynamic conditions. Carbon. 2003;41:2413-24.

26. Mianowski A. Analysis of the thermokinetics under dynamic conditions by relative rate of thermal decomposition. J Therm Anal Calorim. 2001;63:765-76.

27. Mianowski A. Consequences of Holba-Šesták equation. J Therm Anal Calorim. 2009;96:507-13.

28. Holba P, Šesták J. Kinetics with regard to the equilibrium of process studied by non-isothermal techniques. Z Physik Chem Neue Folge. 1972;80:1-20. 